\title{
Case Report and Review of the Literature
}

\section{Retroperitoneal Hibernoma: Exhibition of Three Case Reports and Literature Review}

\author{
Andrea Norte García", Eulàlia Ballester Vázquez, Lorena Cambeiro Cabre, Mireia Solans Coll, José Ignacio Pérez \\ García, Montserrat Clos Enriquez, Antonio Moral Duarte and José Antonio González López.
}

General Surgery, General Surgery Unit (Abdominal Wall, Endocrine, Breast and Mesenchymal Tumours), Hospital de la Santa Creu i Sant Pau, Barcelona, Spain

\author{
A R T ICLE INFO \\ Article history: \\ Received: 29 April, 2021 \\ Accepted: 10 May, 2021 \\ Published: 21 May, 2021 \\ Keywords: \\ Retroperitoneal hibernoma \\ fetal brown adipose tissue \\ retroperitoneal tumor \\ benign tumor \\ lipoma \\ liposarcoma
}

\begin{abstract}
A B S T R A C T
Hibernoma is a rare benign tumor that becomes from the vestiges of fetal brown adipose tissue. It can be located on different regions of the body, being tight the most frequent. Retroperitoneal region is approximately of $9.4 \%$. The first person to describe this histological type was Merkel. To the present, there are only described 25 cases on this location. It has a slowly growth, so it is normally asymptomatic, and it usually presents doing compression of different structures. To diagnose the MRI is the best prove, although biopsy will provide definite diagnosis describing four possible variants. Immunochemistry of $M D M 2$, $C D K 4$ and $p 16$ genes is really important to do the differential diagnosis with well-differentiated liposarcoma (WDLS). Only one extensive review of hibernoma with 170 cases on different regions is published. But there is no review on literature specifically of retroperitoneal region, so this is the purpose of the current study. Following we present three more cases of retroperitoneal hibernoma that we have treat on our Mesenchymal Tumours Unit and a revision of the previously published.
\end{abstract}

Case Description

Case 1

The first case is a 49-year-old female patient with a history of childhood asthma, appendectomy and surgery for a uterine myoma in 1998. She was diagnosed with carcinoma in situ with focus of invasion in the upper left quadrant of the left breast. Extension study of the neoplasia was performed with thoraco-abdominal CT observing a right perirenal mass measuring $11 \times 9 \mathrm{~cm}$ with predominantly fatty content (Figure 1), initially classified as an extra-adrenal myelolipoma. For the differential diagnosis of the lesion, MRI was performed and the diagnosis of retroperitoneal liposarcoma could not be dismissed. The patient was referred to our center for evaluation. The case was presented to the mesenchymal tumor committee, which decided to perform a preoperative $14 \mathrm{G}$ tru-cut biopsy. The results found a well-differentiated adipose tumor suggestive of liposarcoma. The MDM2 gene (12q15) was determined by FISH, which was negative. Despite this negative result, the radiological image was suggestive of liposarcoma because of the presence of septum, so an en bloc excision of the retroperitoneal mass and adjacent organs was considered.

Joint surgery was performed on the breast and the right retroperitoneal mass. In the first stage, a left mastectomy and selective sentinel lymph node biopsy were performed. In the second stage, the right retroperitoneal mass was excised en bloc, which included the right kidney, the adrenal gland and the ipsilateral ureter. There were not adhesions at the level of the colon and the mass was in contact with anterior limit of right psoas muscle. Excision was performed together with a nephrectomy and right adrenalectomy. The surgery was uneventful, and the patient was discharged on the third postoperative day without incident. Pathological anatomy of the breast confirmed the diagnosis of infiltrating lobular carcinoma with extensive component of pleomorphic lobular carcinoma in situ and micropapillary ductal carcinoma in situ. Meanwhile, pathological anatomy of the retroperitoneal mass showed a $28 \times 23 \times 5 \mathrm{~cm}$ tumor consisting predominantly of adipocytes, with cells of multivacuolated cytoplasm

${ }^{*}$ Correspondence to: Andrea Norte García, General Surgery Resident, General Surgery Unit (Abdominal Wall, Breast, Endocrinology and Mesenchymal Tumours), Hospital de la Santa Creu i Sant Pau, Barcelona, Spain; Tel: 664850174; E-mail: anorte95@gmail.com 
and central or eccentric nucleus reminiscent of a lipoma-like hibernoma, with no signs of cellular dedifferentiation, mitosis or necrosis (Figure 2). The tumor surrounded the kidney, but did not infiltrate it, as did the

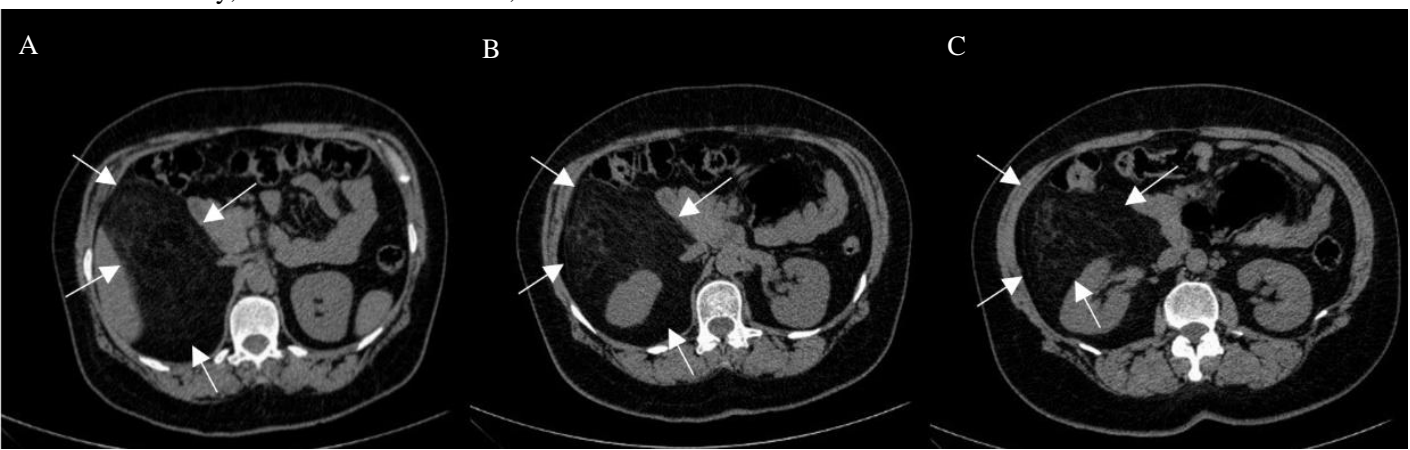

Figure 1: A-C) It is observed a right retroperitoneal mass (between arrows) from inferior marge liver to lateral right psoas muscle. The mass extents from anterior pararenal area involving right kidney with fatty attenuation.

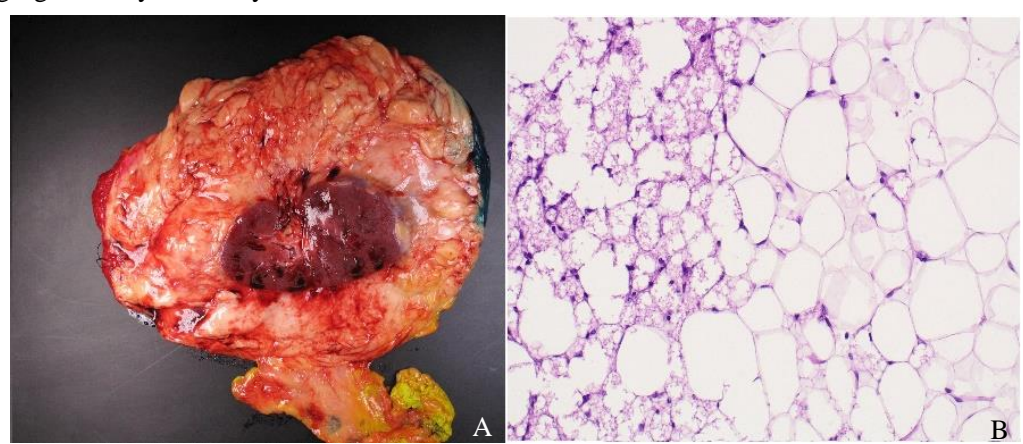

Figure 2: A) Macroscopic anatomy of retroperitoneal mass: it is yellow to brown with a capsule involving the right kidney. B) Microscopic anatomy of retroperitoneal mass where it can be seen mature adipocytes with areas of brown fat cells with multivacuolysed, granular and eosinophilic cytoplasm, that remembered lipoma-like hibernoma variant. There are no areas of dedifferentiation.

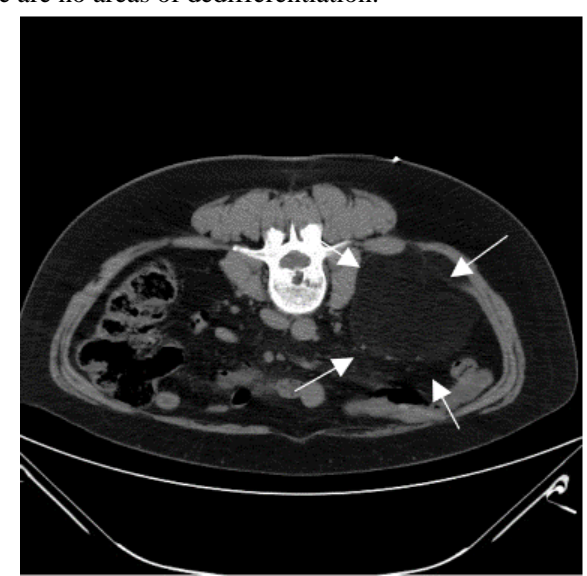

Figure 3: It is observed a mass on left lumbar fossa (between arrows) with fatty attenuation between transverse and internal oblique muscles. There is no structure invasion.

\section{Case 2}

The second case is a 63-year-old female patient with a history of ulcerative colitis, monoclonal gammopathy, phyllodes tumor of the right breast, type 2 diabetes mellitus and hiatus hernia, followed up for left lumbar pain of seven months. An MRI showed by chance a left retroperitoneal mass located in the left lumbar fossa measuring $77 \times 85 \times 89 \mathrm{~cm}$. A control abdominal CT scan was performed to determine the evolution of the lesion, showing an enlargement of the mass measuring $80 \times 87 \times 100 \mathrm{~cm}$. It was located between the muscular planes of the transverse muscle and the internal oblique muscle of the abdomen adrenal gland, which was free of infiltration. The $M D M 2$ gene study of the surgical specimen was also negative. 


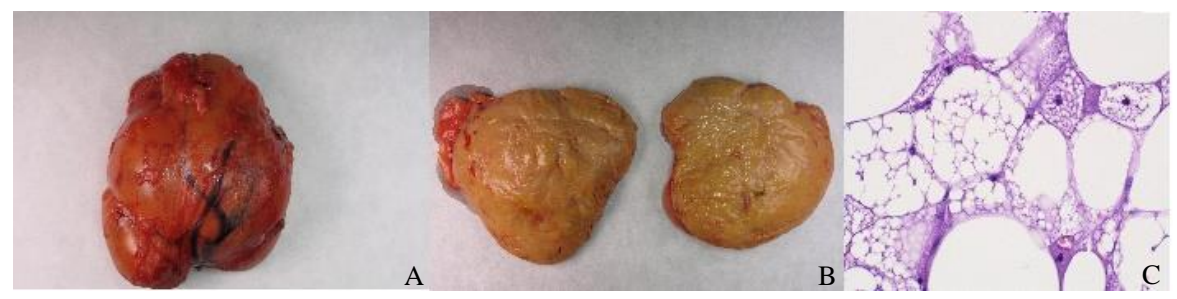

Figure 4: A) Macroscopic anatomy of retroperitoneal mass. It is yellow to brown, multilobulated and involving with a capsule. B) If we cut it out it turns to be pale yellow without areas of necrosis or hemorrhage. C) Microscopic anatomy with brown fat cells with multivacuolysed, granular and eosinophilic cytoplasm, that remembered typical hibernoma variant. There are no malignancy signs.

Surgery was indicated due to the patient's clinical condition. A single excision of the lesion was performed by supraumbilical laparotomy. During surgery, a left retroperitoneal mass was observed lateral to the left psoas muscle, with no adhesions to adjacent structures, which was introduced into the thickness of the transverse and internal oblique muscles of the latero-posterior abdominal wall. Subsequently, the abdominal wall was reconstructed with a biological mesh. The surgery was uneventful, and the patient was discharged on the third postoperative day without incident. The pathological anatomy showed a tumor measuring 11x9x6 cm made up of more than seventy percent brown fat cells with multivacuolysed, granular and eosinophilic cytoplasm, with occasional globules of mature adipose tissue, with no malignancy criteria, confirming the diagnosis of hibernoma (Figure 4).

\section{Case 3}

Finally, the third case is a 54-year-old female patient with history of hypothyroidism, with a palpable mass on right inguinal region. An abdominal CT scan was performed with the suspicion of inguinal hernia, observing a mass that could be compatible with the diagnosis of intrapelvic right lipoma measuring 60x50x180 mm (Figure 5). It had a prolongation to the leg through a defect of $5 \mathrm{~cm}$ on the abdominal wall, laterally to inferior epigastric vessels, without malignancy signs. As previously cases, she was referred to our center for surgical evaluation. On the mesenchymal tumor committee, it was also decided to perform a preoperative $14 \mathrm{G}$ tru-cut biopsy. The sample showed mature adipocytes compatible with lipoma diagnosis and some areas of classic variant of hibernoma with microvacuolysed cytoplasm, being MDM2 (12q15) also negative.

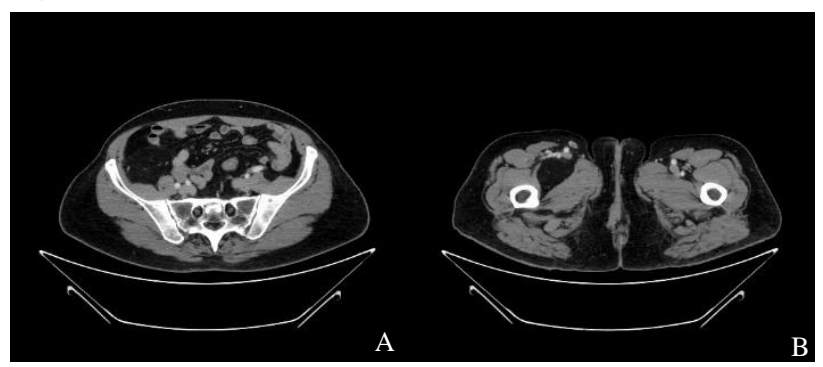

Figure 5: A) It is observed an encapsulated lesion with fatty attenuation with extension from anterior marge of iliac bone to psoas muscle and isquiopubic branch. B) It is localised lateral to iliac and femoral vessels, leaving abdominal cavity to enter to the pelvic region between a defect on the abdominal wall of $5 \mathrm{~cm}$, laterally to epigastric vessels. On leg, it founds between pectineal and right iliac muscles.

Surgery was indicated because patient's clinical condition and a single enucleation was performed. During surgery we did an oblique right inguinal incision with prolongation through the leg. A lipomatous tumor measuring $15 \mathrm{~cm}$ approximately was observed, being extraperitoneal, and located in right pelvis with extension to psoas muscle, inferior to femoral nerve. It was a joint intervention with orthopaedic surgeons. The dissection of the mass was in the preperitoneal space and the resection could succeed without the opening of peritoneum, with the preservation of femoral nerve. The surgery was uneventful, and the patient was discharged on the fourth postoperative day without incident. The pathological anatomy showed a tumor measuring $19 \times 7 \times 3 \mathrm{~cm}$ made up of more than seventy percent brown fat cells confirming also the diagnosis of hibernoma, being $M D M 2$ gene (12q15) also negative.

\section{Discussion}

Hibernoma or brown fat tumor is a rare benign tumor that it is believed to be derived from the remnants of brown adipose tissue. It was first described by Merkel in 1906 with the name of sebaceous gland or pseudolipoma, but it was not until 1924 that Gery named it hibernoma because of the parallelism with the hibernating glands of animals $[1,2]$. This is due to the high number of mitochondria, the high glucose metabolism and the supposed thermoregulatory function related on birth [3]. This type of tissue is characteristic of the new-born and infant, predominating in the paraoesophageal, paratracheal, posterior neck and interscapular regions, with a progressive reduction in the eighth week of life. Previously it was believed that these regions were the most frequent site of hibernoma, but the latest review published by Furlong et al. with 170 cases describes the thigh as the most frequent site, representing $30 \%$ of the total, followed by the shoulder, back, neck, thorax, arm, retroperitoneum, axilla, groin, supraclavicular area, buttock, scalp, abdominal wall, chest, spermatic cord and, lastly, scrotum and perineum [4]. It should be noted, therefore, that the retroperitoneal location is infrequent, being approximately $9.4 \%$ [5].

In terms of epidemiology, hibernoma generally accounts for less than $2 \%$ of benign tumors and $1 \%$ of all tumors containing adipocytes [6]. Another epidemiological aspect to note is the possible link between hibernoma and multiple endocrine neoplasia type 1 . To date, four cases have been described in the literature that reflect this association, being hibernomas of a different location other than the retroperitoneal: two in the buttock, one in the posterior area of the trochanter and another in the thigh [7]. They are usually tumors typical of young adults and as regards frequency according to sex, it was thought that there was a slight predominance in women, although the series published by Furlong et al. shows a slightly higher tendency in men with a mean age of 37.1 years [4]. Two of three cases we have described, had the coincidental association with breast tumors. The first case was a carcinoma and the second a phyllodes tumor. Despite being histological types distinct from 
hibernoma, future case series will be necessary to rule out or confirm this association, as is the case with multiple endocrine neoplasia type 1. Clinically, these are slow-growing tumors, most of which are asymptomatic or show symptoms due to compression of structures. For diagnosis, ultrasound will show a hyperechoic lesion with increased vascularisation on Doppler. CT with contrast enhances the inner septa and MRI is the diagnostic test of choice. It shows a well-defined soft tissue lesion, without invasion of structures, hyperintense with respect to muscle and hypointense with respect to fat in T1. It also shows an absence of signal suppression for fat tissue on STIR or Fast Spin Echo images in $\mathrm{T} 2$ sequence [8].

Finally, because of it is a metabolically active tissue, it is frequently detected incidentally with a PET scan with FDG [9]. Preoperatively, a core needle biopsy $(\mathrm{CNB})$ can be performed, although the final pathology report after surgical excision provides the definitive diagnosis. Furlong et al. described four histological variants with typical hibernoma being the most frequent, followed in frequency by myxoid, lipoma-like and spindle cell variants [4]. The typical variant is characterised by a lobular pattern composed of eosinophilic polygonal cells with a central nucleus and lipid-containing multivacuolated cells [10]. It is important to recognise the other histological types of hibernoma for differential diagnosis with well-differentiated liposarcoma, which would have a different surgical management. It is for this reason that immunohistochemistry could help us to differentiate these tumors formed by adipocytes, since hibernomas express the MDM2, CDK4 and p16 gene to a lesser extent, with FISH amplification of the MDM2 gene being negative. This is contrary to dedifferentiated liposarcoma, which tends to overexpress $M D M 2, C D K 4$ and p16 [11]. Furthermore, from a cytogenetic point of view, almost all hibernomas have alterations in the 11q13 region of the homologous chromosomes: genome rearrangements, translocations or deletions. As a result, the regions that translate the tumor suppressor genes MEN1 (multiple endocrine neoplasia type 1) and AIP (aryl hydrocarbon receptor-interacting protein) may be altered [6]. This cytogenetic alteration could therefore explain the possible link between hibernoma, and multiple endocrine neoplasia type 1 mentioned above [7]. Furthermore, the four cases included in the review by Marchand $e t$ al. report de novo mutations in the MEN1 gene in three of them, concluding that hibernoma may be associated with non-familial forms of multiple endocrine neoplasia type 1 , and that there may be other cytogenetic alterations and genetic rearrangements on chromosome 11 [7]. Macroscopically, they are characterised by well-defined, slightly lobulated, shiny masses, ranging in colour from yellow to brown [6].

Table 1: Characteristics of retroperitoneal hibernoma patients.

\begin{tabular}{|c|c|c|c|c|c|c|c|}
\hline Author & Year & Sex & Age & Presentation & Image & Association & $\begin{array}{l}\text { Malignance } \\
\text { Recurrence }\end{array}$ \\
\hline Rigor [12] & 1986 & $\mathrm{~F}$ & 24 & Abdominal distension & Echography + CT scan & NO & NO \\
\hline Ward [13] & 1990 & $\mathrm{~F}$ & 31 & Pleuritic pain & Echography + CT scan & NO & NO \\
\hline Boleslaw [14] & 1994 & $F$ & 39 & $\begin{array}{l}\text { Abdominal pain }+ \text { hypertension }+ \\
\text { vomiting }\end{array}$ & CT scan & Angiomyolipoma & NO \\
\hline Sansom [15] & 1999 & $\mathrm{~F}$ & 29 & Lumbar pain + anorexia + vomiting & CT scan & $\mathrm{NO}$ & $\mathrm{NO}$ \\
\hline Gülmez [16] & 1999 & $\mathrm{~F}$ & 28 & Abdominal pain & Intravenous urography & $\mathrm{NO}$ & NO \\
\hline Furlong [4] & 2001 & No data & No data & Abdominal pain & No data & NO & NO \\
\hline Cantisani [17] & 2003 & M & 38 & Abdominal pain & $\mathrm{TC}$ & NO & NO \\
\hline $\begin{array}{l}\text { Gómez-Sotelo } \\
{[18]}\end{array}$ & 2010 & $\mathrm{~F}$ & 46 & Lumbar pain & MRI & NO & NO \\
\hline Delsignore [19] & 2010 & $F$ & 51 & Abdominal pain & $\begin{array}{l}\text { Echography }+ \\
\text { intravenous urography }\end{array}$ & $\mathrm{NO}$ & $\mathrm{NO}$ \\
\hline Pandya [20] & 2011 & $\mathrm{~F}$ & 36 & $\begin{array}{l}\text { Abdominal distension }+ \text { abdominal } \\
\text { pain }\end{array}$ & Echography + CT scan & NO & NO \\
\hline Yohannan [21] & 2011 & M & 28 & Asymptomatic & CT scan & NO & $\mathrm{NO}$ \\
\hline Collado [22] & 2011 & $\mathrm{~F}$ & 3 months & Prenatal diagnosis & Echography + CT scan & $\mathrm{NO}$ & NO \\
\hline $\begin{array}{l}\text { Oñate-Celdrán } \\
{[5]}\end{array}$ & 2014 & $F$ & 59 & Abdominal pain & Echography + CT scan & NO & $\mathrm{NO}$ \\
\hline Treppiedi [23] & 2017 & $\mathrm{~F}$ & 58 & Abdominal pain & Echography + MRI & $\mathrm{NO}$ & $\mathrm{NO}$ \\
\hline $\begin{array}{l}\text { Lévano-Linares } \\
{[9]}\end{array}$ & 2018 & M & 44 & Abdominal pain & $\begin{array}{l}\text { CT scan + MRI + } \\
\text { SPECT-CT }\end{array}$ & Pheochromocytoma & NO \\
\hline Pothen [24] & 2018 & M & 26 & Blurry vision & PET-CT & Ulcerative colitis & $\mathrm{NO}$ \\
\hline HSP1 & 2019 & $\mathrm{~F}$ & 49 & Asymptomatic & CT-scan + MRI & Breast carcinoma & $\mathrm{NO}$ \\
\hline HSP2 & 2020 & $\mathrm{~F}$ & 63 & Lumbar pain & CT scan & Phylloid tumor & NO \\
\hline HSP3 & 2021 & $\mathrm{~F}$ & 54 & Palpable mass & CT scan & NO & $\mathrm{NO}$ \\
\hline
\end{tabular}

M: Male; F: Female. 
To our knowledge, a total of 15 cases of retroperitoneal hibernoma have been published in the literature (Table 1), 25 in total if we add the 10 reported in the series by Furlong et al. [4, 5, 9, 12-24]. Of the 15 published in isolation, 11 were in women and 4 in men. If we add those reported by us, we find a frequency of $77.78 \%$ in women (14/18) and $22.22 \%$ in men $(4 / 18)$ with a mean age of 39.05 years, excluding the pediatric case of Collado et al. [20]. These three cases that we have managed in our unit have in common to be presented all in woman between 45 and 65 years old. Two of them were a casual diagnosis on images and the other one was because of local pain. All cases had been through a preoperatory biopsy that informed hibernoma in two of them and liposarcoma on the other one. This fact had an impact on surgical management because the first patient needed en bloc resection meanwhile other two cases got an enucleation surgery. For this reason, pathological diagnosis is crucial to choose the type of surgery, that is really different if we confront an hibernoma or a liposarcoma. No recurrence or malignancy of this type of tumor has been reported to date in any of the cases described, neither nor our cases. For this reason, hibernoma is considered a benign tumor in which single surgical excision of the lesion by enucleation is sufficient to cure the patient.

\section{Conclusion}

Retroperitoneal hibernoma is a rare benign tumor in which the definitive diagnosis is obtained by pathological anatomy. It is important from a surgical management point of view to perform a core needle biopsy and immunohistochemical analysis to make the differential diagnosis with well-differentiated liposarcoma, as the approach and aggressiveness of surgery will be very different. Complete excision of the hibernoma is considered to cure the patient and no recurrence or malignancy has been reported to date.

\section{REFERENCES}

1. Merkel H (1906) On a pseudolipoma of the breast (peculiar fat tumors). Beitr Pathol Anat 39: 152-157.

2. Gery L (1914) In discussion of MF Bonnel's paper. Bull Mem Soc Anat 89: $111-112$.

3. Heaton JM (1972) The distribution of brown adipose tissue in the human. J Anat 112: 35-39. [Crossref]

4. Furlong MA, Fanburg Smith JC, Miettinen M (2001) The Morphologic Spectrum of Hibernoma. Am J Surg Pathol 25: 809-814. [Crossref]

5. Oñate Celdrán J, Sánchez Rodríguez C, Gonzalez Valverde FM, García Escudero D, Fontana Compiano Lo (2014) Presentación de un caso y revisión de la literatura. Gastroen Hepatol 37: 246-247.

6. Antonescu C (2020) Soft tissue and bone tumours. Lyon: Int Agen Res Can 5: 3 .

7. Marchand L, Decaussin Petrucci M, Giraud S, Cotton F, Thivolet C et al. (2017) Hibernoma and multiple endocrine neoplasia type 1 syndrome: A non-fortuitous association? A case report and literature review. Ann Endocrinol (Paris) 78: 194-197. [Crossref]
8. Lee JC, Gupta A, Saifuddin A, Flanagan A, Skinner JA et al. (2006) Hibernoma: MRI features in eight consecutive cases. Clini Radiol 61: 1029-1034. [Crossref]

9. Lévano Linares DC, Ruiz Tovar J, Muñoz Najar AG, Familiar V, Durán Poveda M (2018) Un caso raro de hibernoma retroperitoneal bilateral identificado por 123I-MIBG SPECT/TC en un paciente con feocromocitoma unilateral. Cir Esp 96: 595-597.

10. Hallin M, Schneider N, Thway K (2016) Well-Differentiated Liposarcoma With Hibernoma-Like Morphology. Int J Surg Pathol 24: 620-622. [Crossref]

11. Thway K, Flora R, Shah C, Olmos D, Fisher C (2012) Diagnostic utility of p16, CDK4, and MDM2 as an immunohistochemical panel in distinguishing well-differentiated and dedifferentiated liposarcomas from other adipocytic tumors. Am J Surg Pathol 36: 462-469. [Crossref]

12. Rigor VU, Goldstone JE, Jones J, Bernstein R, Gold MS et al. (1986) Hibernoma: A case report and discussion of a rare tumour. Cancer 57: 2207-2211. [Crossref]

13. Ward SC, Hornsby VP (1990) "The dormouse is asleep again" said the Hatter, and he poured a little hot tea upon is nose (Lewis Carroll). Case of the month. Br J Radiol 63: 733-734.

14. Liwnicz BH, Weeks DA, Zuppan CW et al. (1994) Extrarenal angiomyolipoma with melanocytic and hibernoma-like features. Ultrastruc Pathol 18: 443-448. [Crossref]

15. Sansom HE, Blunt DM, Moskovic EC (1999) Large retroperitoneal hibernoma- -CT findings with pathological correlation. Clin Radiol 54: 625-627. [Crossref]

16. Gülmez I, Dogan A, Balkanli S, Yilmaz U, Karacagil M et al. (1997) The first case of periureteric hibernoma. Case report. Scand J Urol Nephrol 31: 203-204. [Crossref]

17. Cantisani V, Mortele K, Glickman J, Ricci P, Passariello R et al. (2003) Large retroperitoneal hibernoma in an adult male: $\mathrm{CT}$ imaging findings with pathologic correlation. Abdom Imaging 28: 721-724. [Crossref]

18. Sotelo AG, Molina MC, López RA, Ramón JA, Morillas DR (2010) Retroperitoneal hibernoma. Cir Esp 88: 345-346. [Crossref]

19. Delsingore A, Ranzoni S, Arancio M, Marchetti C, Landi G et al. (2010) Kidney hibernoma: case report and literature review. Arch Ital Urol Androl 83: 189-191. [Crossref]

20. Pandya A, Wasnik AP (2011) Presacral hibernoma: Radiologicpathologic correlation. Indian J Radiol Imaging 21: 270-273. [Crossref]

21. Yohannan J, Feng T, Allaf ME (2011) Retroperitoneal Hibernoma in a 28-Year-old Man. Urology 78: 320-321. [Crossref]

22. Collado L, Sierre S, Bolasec A, Lipsich J (2011) Hibernoma: tumor retroperitoneal de grasa parda. Informe de un caso pediátrico. Arch Argent Pediatr 109: 126-129.

23. Treppiedi E, Zimmitti G, Manzoni A, Sega V, Guerini F et al. (2017) Extra peritoneal giant pelvic hibernoma: a case report. Int J Surg Case Rep 12: 1-4. [Crossref]

24. Pothen L, D'Abadie P, Kozyreff A, Mourin A, Coubeau L (2018) Hibernoma mimicking liposarcoma. Lancet 392: 244. [Crossref] 